\title{
Development of a microwave sample preparation method for the determination of arsenic in humus and moss samples by graphite furnace atomic absorption spectrometry
}

\author{
P. Perämäki ${ }^{1 *}$, M. Pesonen ${ }^{1}$ and J. Piispanen ${ }^{2}$ \\ ${ }^{1}$ University of Oulu, Department of Chemistry, PO. Box 3000, FIN-90014 University of Oulu, Finland \\ ${ }^{2}$ Finnish Forest Research Institute, Muhos Research Station, Kirkkosaarentie 7, FIN-91500 Muhos, Finland
}

\begin{abstract}
Two sample decomposition methods were optimized for the determination of arsenic by graphite furnace atomic absorption spectrometry (GFAAS) in moss and humus samples. In the first method, $5,0 \mathrm{ml}$ of $\mathrm{HNO}_{3}$ and $3,0 \mathrm{ml}$ of $\mathrm{H}_{2} \mathrm{O}_{2}$ were used for the decomposition of $500 \mathrm{mg}$ of sample. When humus samples were decomposed in this way a slight, undissolved residue remained. Therefore, another sample decomposition method, including hydrofluoric acid, was also tested $\left(5,0 \mathrm{ml} \mathrm{HNO}_{3} ; 3,0 \mathrm{ml}\right.$ $\mathrm{H}_{2} \mathrm{O}_{2} ; 0,4 \mathrm{ml} \mathrm{HF} ; 2,5 \mathrm{ml} \mathrm{H} \mathrm{BO}_{3}$ ). Pyrolytically coated graphite tubes, equipped with integrated or L'vov platfoms, were used in the determination of arsenic by GFAAS. Palladium-magnesium nitrate was used as a matrix modifier. Several reference materials (e.g. humus, moss, lichen, sea lettuce) were analyzed.
\end{abstract}

Keywords. Arsenic - graphite furnace atomic absorption spectrometry - microwave sample decomposition - humus and moss samples.

\section{Introduction}

Arsenic is emitted into the atmosphere globally mainly from coal combustion, and more locally from the mining industry (mainly nickel-copper smelters). Minor sources of airborne arsenic emissions are glass industries and the use of arsenic in pesticides and wood preservatives. Arsenic is moderately toxic to plants, but highly toxic and carcinogenic to mammals. Natural arsenic levels in plants seldom exceed $1 \mathrm{mg} / \mathrm{kg}$ [1].

The atmospheric heavy metal deposition of ten elements has been monitored by using mosses as bioindicators [2]. The Muhos Research Station of the Finnish Forest Research Institute (Metla) has been in charge of the international deposition survey in Finland. The next survey, concerning nearly all European countries, will be done in the years 2000-2001. The concentrations of heavy metals in moss are closely correlated to atmospheric deposition because mosses, especially the carpetforming species, obtain most of their nutrient supply directly from precipitation and from dry deposition of air-borne particles. In the main area of investigation, the arsenic concentrations of mosses varied between 0.2 and $0.6 \mathrm{mg} / \mathrm{kg}[2]$.

In order to reliably analyze samples containing such small amounts of arsenic, much attention must be given to the digestion and measurement methods used. There are many advantages in using microwave digestion for the decomposition of plant samples. These include decreased digestion times, smaller amounts of acids required, reduced contamination during the digestion procedure and avoidance of using perchloric acid. Also, the possibility to control the digestion conditions makes microwave digestion more accurate and precise. In addition to sample digestion, microwave assisted extraction for speciation purposes is also possible $[3,4]$.

The determination of arsenic in environmental samples by graphite furnace atomic absorption spectrometry (GFAAS) has several difficulties. Many arsenic compounds are highly volatile and losses of arsenic may occur during the ashing phase [5]. Spectral interference are observed especially when continuum source background correction is used. Spectral interference are associated with the atomization step of the measurement and arise from the presence of, for example, phosphate, iron, and aluminium $[6,7,8]$.

The purpose of this investigation was to develop a digestion method for the mineralization of plant samples (especially moss) and to optimize the GFAAS method for the determination of arsenic. The work for the first goal included the comparison of different acid mixtures and the optimization of the time and power of the microwave digestion. The decomposition methods should be reasonably accurate and rapid for the decomposition of large numbers of bioindicator samples. 


\section{Original articles}

\section{Materials and methods}

\section{Graphite furnace determinations}

A Perkin Elmer Zeeman/3030 atomic absorption spectrometer, equipped with a HGA-600 graphite furnace and an AS60 autosampler was used in the measurements. An electrodeless discharge lamp (EDL) was used as the light source. Pyrocoated graphite tubes with integrated platforms or L'vov platforms were used for arsenic atomization; $20 \mu \mathrm{l}$ of sample solution and $10 \mu \mathrm{l}$ of matrix modifier solution were injected into a graphite furnace. Integrated absorbance values were used for arsenic quantification. The instrumental parameters used were as follows: wavelength $193.7 \mathrm{~nm}$; slit width $0.7 \mathrm{~nm}$; measurement time $5.0 \mathrm{~s}$ and EDL power $8 \mathrm{~W}$. Peak area was used for quantitation. The following graphite furnace program was used (ramp in s/temperature in ${ }^{\circ} \mathrm{C} /$ hold time in s). Dry 1: 1/90/5. Dry 2: 20/140/15. Ash: 15/1300/15 (integrated platform) or 15/1500/15 (L'vov platform). Cool down: 1/20/5. Atomization: 0/2200/5. Clean up: 1/2650/5. Cool down: 1/20/5. The internal argon flow of $300 \mathrm{ml} \mathrm{min}^{-1}$ was stopped during atomization.

\section{Reagents}

The ultrapure water used thoughout this work was purified with an ELGA UHG apparatus. A commercial stock solution for arsenic $(1000 \mathrm{mg} / \mathrm{l})$ was obtained from Merck. The other reagents used were as follows: argon (AGA, 99,99\%), boric acid $\left(\mathrm{H}_{3} \mathrm{BO}_{3}\right.$, Merck, suprapure), magnesium nitrate $\left(\mathrm{Mg}\left(\mathrm{NO}_{3}\right)_{2} \cdot 6 \mathrm{H}_{2} \mathrm{O}\right.$, Merck, suprapure), palladium (Pd, Aldrich, 99,999\%), nitric acid (70 \% $\mathrm{HNO}_{3}$, J.T. Baker, p.a. or instra-analyzed), hydrofluoric acid (40\% HF, Merck, suprapure), hydrogen chloride (37 \% HCl, J.T. Baker, instraanalyzed) and hydrogen peroxide $\left(30 \% \mathrm{H}_{2} \mathrm{O}_{2}\right.$, Riedel-de Haën, for analyse).

A palladium modifier was prepared by dissolving $300 \mathrm{mg}$ of $\mathrm{Pd}$ powder in $1 \mathrm{ml}$ of conc. $\mathrm{HNO}_{3}$ and $10 \mu \mathrm{l}$ of conc. $\mathrm{HCl}$. The dissolution process was sped up by heating. The modifier solution was diluted to $100 \mathrm{ml}$ with water. A magnesium nitrate modifier solution was prepared by dissolving $350 \mathrm{mg}$ of $\mathrm{Mg}\left(\mathrm{NO}_{3}\right)_{2} \cdot 6 \mathrm{H}_{2} \mathrm{O}$ in $100 \mathrm{ml}$ of water. The two modifier solutions were mixed together in order to obtain a solution that contained $1500 \mathrm{mg} / \mathrm{l} \mathrm{Pd}$ and $1000 \mathrm{mg} / \mathrm{l}$ $\mathrm{Mg}\left(\mathrm{NO}_{3}\right)_{2}$. Ten $\mu \mathrm{l}$ of this modifier, containing $15 \mu \mathrm{g}$ of $\mathrm{Pd}$ and $10 \mu \mathrm{g}$ of $\mathrm{Mg}\left(\mathrm{NO}_{3}\right)_{2}$, was injected into the graphite tube.

The reference materials used in this work are given in table I. The humus and moss reference materials are prepared by the Finnish Forest Research Institute [9]. The Puolanka materials are from uncontaminated area; the Harjavalta materials originate from close to the smelter.

\section{Sample decomposition methods}

Samples were decomposed in a microwave oven, model MDS $81 \mathrm{D}$ (CEM Corporation). The microwave power of this unit can be adjusted with $1 \%$ increments; the calibrated
Table I. The reference materials used in arsenic determinations.

\begin{tabular}{lcc}
\hline Sample & Source & $\begin{array}{c}\text { Recommended/ Certified value } \\
\text { As/mg kg-1 }\end{array}$ \\
\hline Humus (Harjavalta) & Metla & $6.6 \pm 0.6(n=15)^{\mathrm{a}}$ \\
Humus (Puolanka) & Metla & $1.76 \pm 0.04(n=5)^{\mathrm{a}}$ \\
Moss (Harjavalta) & Metla & $0.98 \pm 0.07(n=14)^{\mathrm{a}}$ \\
Moss (Puolanka) & Metla & $0.105 \pm 0.007(n=11)^{\mathrm{a}}$ \\
Sea lettuce & BCR 279 & $3.09 \pm 0.20^{\mathrm{b}}$ \\
Lichen & BCR 482 & $0.85 \pm 0.07^{\mathrm{b}}$ \\
\hline
\end{tabular}

Metla $=$ Finnish Forest Research Institute

$\mathrm{BCR}=$ Community Bureau of Reference; certified reference materials

${ }^{a}$ Recommended value \pm 1 standard deviation ( $n=$ number of individual results)

${ }^{\mathrm{b}}$ Certified value and $95 \%$ confidence interval

maximum output power was $632 \mathrm{~W}$. Teflon PFA LDV-vessels (CEM Corporation) were used in sample preparation.

Two microwave digestion methods were tested in order to decompose the moss and humus samples for the arsenic determinations. In both methods, concentrated nitric acid was used, since it is a powerful oxidizing agent. The oxidation power can be further enhanced by the addition of hydrogen peroxide. In addition, hydrofluoric acid is also sometimes used due to its ability to dissolve silicates [10,11]. The first method tested, hereafter Method 1, was based on the procedure described by Lippo et al. [12]. In this method, $500 \mathrm{mg}$ of sample was weighed in the microwave digestion vessel. Five $\mathrm{ml}$ of conc. $\mathrm{HNO}_{3}$ and $3 \mathrm{ml}$ of $\mathrm{H}_{2} \mathrm{O}_{2}$ were added, and the vessel was closed. Twelve samples were heated in the microwave oven. Three different modifications of decomposition Method 1, consisting of three stages, were tested (power in W/time in min). Program A: 60/5, 630/2, 390/6. Program B: 60/5, 630/2, 460/10. Program C: 60/5, 630/2, 630/10.

A residue was observed in some samples after decomposition with Method 1, even though longer decomposition times and higher microwave power settings were used. Therefore, $0.4 \mathrm{ml}$ of hydrofluoric acid was included in Method 2 to achieve complete dissolution of the samples (power in W/time in min): 60/5, 630/2, 630/10, 630/5. In this method, the samples were allowed to cool down after stage three. Then $2,5 \mathrm{ml}$ of saturated boric acid was added to the samples and the phase four was run. Boric acid complexes the excess fluoride ions and assists the dissolution of precipitated fluoride compounds. After decomposition, the samples were diluted to $25 \mathrm{ml}$ with water in both Methods 1 and 2.

\section{Results and discussion}

\section{Matrix modification}

Matrix modification is an essential step in the determination of easily volatile elements by GFAAS. The most common matrix modifiers used in arsenic determinations are 
palladium, palladium-magnesium nitrate and nickel nitrate. Pd- $\mathrm{Mg}\left(\mathrm{NO}_{3}\right)_{2}$ was selected as a modifier since memory effects are observed when the nickel modifier is used [13]. An interelement compound is formed between arsenic and palladium, which has a higher heat of vaporization than pure arsenic. Therefore, a higher ashing temperature can be used and the effects of interference are diminished. Magnesium nitrate behaves as an ashing aid during the thermal pretreatment step in graphite furnace determinations.

Spectral interferences caused by aluminium and phosphate are possible at the primary resonance line $(193.7 \mathrm{~nm})$ of arsenic. It should be possible to almost eliminate these interferences with the Zeeman background correction technique $[14,15,16]$.

Characteristic mass for arsenic is quite high, and therefore a rather large absolute mass of arsenic should be injected into a graphite tube in order to obtain a reasonable sensitivity. This means that a higher sample volume should be used or that a preconcentration step is necessary. However, with a larger sample volume, a longer sample drying phase is needed, and there is also a maximum sample volume that can be dispensed onto a platform. Therefore, a sample volume of $20 \mu \mathrm{l}$ was selected for routine use. With very low arsenic concentrations, two or more sample dispensing-drying steps can be used in order to increase the absolute amount of arsenic in the graphite furnace. One should remember that this will also increase the amount of matrix introduced into the furnace.

Ten $\mu$ l of modifier solution was injected onto a sample. Larger volumes of modifier had produced wider and flatter absorption signals, therefore $10 \mu \mathrm{l}$ of modifier was determined to be the optimal volume in arsenic determinations.

\section{Ash-atomization plots}

Optimal ash and atomization temperatures for arsenic in Harjavalta humus samples were measured after decomposition of $500 \mathrm{mg}$ of the sample in microwave oven with 5,0 ml of conc. $\mathrm{HNO}_{3}$ and 3,0 $\mathrm{ml}$ of $30 \% \mathrm{H}_{2} \mathrm{O}_{2}$ (Method 1C). After decomposition the humus sample was diluted to $50 \mathrm{ml}$ with water. The optimum ash and atomize temperatures obtained with an integrated platform tube were $1300^{\circ} \mathrm{C}$ and $2200{ }^{\circ} \mathrm{C}$, respectively (Fig. 1).

Ash-atomization-plots for moss (Harjavalta) and lichen samples were determined using a coated graphite tube, equipped with a L'vov platform. The samples were decomposed according to Method 1C. For the moss and lichen samples, a programmed temperature of $1500{ }^{\circ} \mathrm{C}$ could be used without losses of arsenic. The optimal atomization temperature was around $2200{ }^{\circ} \mathrm{C}$ (Fig. 2 and 3). According to the ash-atomization plots, the furnace program described earlier was established in use for arsenic determinations.

\section{Decomposition of humus and moss samples}

Since humus samples are supposed to be more difficult to decompose than moss samples [17], the three different

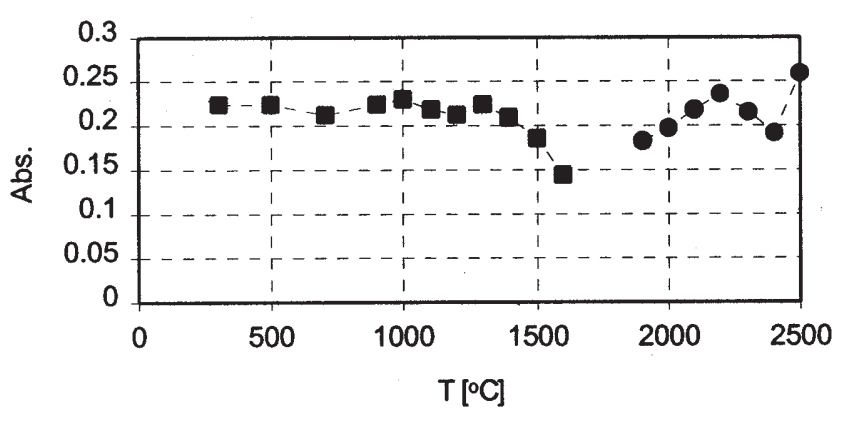

Figure 1. Ash-atomization-plot for Harjavalta humus sample: 1.3 ng of As; modifier: $15 \mu \mathrm{g}$ of $\mathrm{Pd}$ and $10 \mu \mathrm{g}$ of $\mathrm{Mg}\left(\mathrm{NO}_{3}\right)_{2}$. A pyrolytically coated graphite tube with an integrated platform was used.

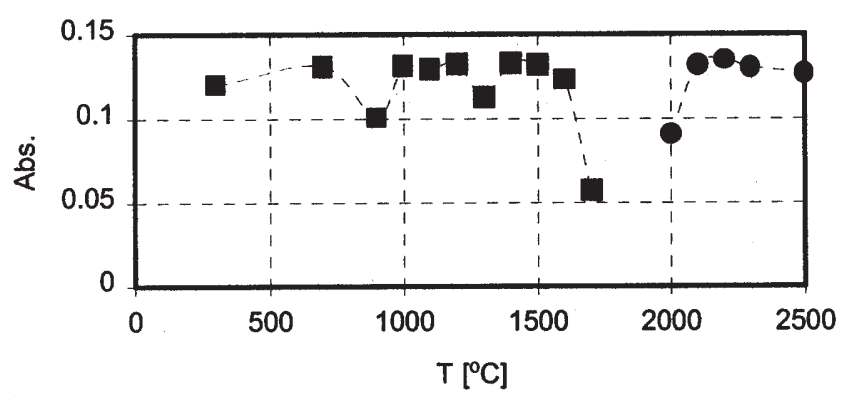

Figure 2. Ash-atomization-plot for Harjavalta moss sample: 0.39 ng of As; modifier: $15 \mu \mathrm{g}$ of $\mathrm{Pd}$ and $10 \mu \mathrm{g}$ of $\mathrm{Mg}\left(\mathrm{NO}_{3}\right)_{2}$. A pyrolytically coated graphite tube with a $L^{\prime}$ vov platform was used.

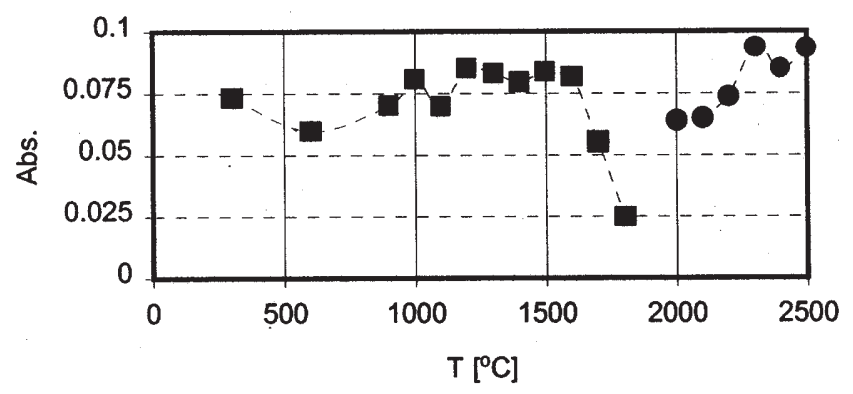

Figure 3. Ash-atomization plot for the lichen sample: $0.34 \mathrm{ng}$ of As; modifier: $15 \mu \mathrm{g}$ of $\mathrm{Pd}$ and $10 \mu \mathrm{g}$ of $\mathrm{Mg}\left(\mathrm{NO}_{3}\right)_{2}$. A pyrolytically coated graphite tube with a $\mathrm{L}^{\prime}$ vov platform was used.

variations of the microwave decomposition Method 1 were tested with humus samples collected from Puolanka and Harjavalta. Measurements were carried out using pyrolytically coated graphite tubes equipped with an integrated platform. The decomposition with any variations of the Method 1 did not result in complete dissolution; a black residue was observed every time the samples were decomposed. However, the recoveries for arsenic increased when 
decomposition time and power settings were increased. The results obtained are shown in table II.

The different variations of decomposition Method 1 were also tested with the Harjavalta moss samples. As a general rule, the moss samples should decompose more easily with the strong oxidants used, since the sample matrix is more simple compared to those of the humus samples (i.e. the matrix of moss samples contains mostly organic matter; for example the ash contents of Puolanka moss and humus samples are $2.0 \%$ and $4.3 \%$, respectively). When the moss samples were decomposed with the Method 1, a clear solution was obtained with every program A-C. The recoveries for arsenic in Harjavalta moss samples also increased when the microwave oven power settings and decomposition times were increased (Tab. II). The decomposition program termed "C" gave the best recoveries, and it was selected for further use.

Another microwave decomposition method, including hydrofluoric acid in the reagent mixture, was tested in order to achieve a complete dissolution of the humus sample $[18,19]$. With Method 2 the decomposition is carried out in four stages. The first three stages were the same as in Method 1C. After stage three the samples were cooled down, and saturated boric acid was added in order to mask the free fluoride ions and to assist the dissolution of the precipitated fluorides $[14,20]$.

The recoveries of pure aqueous As standards were also measured when microwave digestion Methods $1 \mathrm{C}$ and 2 were employed. A few tens of microliters of arsenic standard solution were added into the microwave vessel in order to obtain a concentration of $30-72 \mu \mathrm{g} / \mathrm{l}$ in the final test solutions (the dilution of the acid matrix in the decomposition vessel was negligible). The results in table III show that no arsenic losses occur during the sample decomposition procedure. The acid concentration of the sample had no significant effect, since a good recovery was obtained when the acid matrix of the spiked digestion mixture was diluted either to 50 or $25 \mathrm{ml}$.

\section{Results obtained by Methods 1C and 2}

The results obtained for the different samples with the microwave dissolution Methods $1 \mathrm{C}$ and 2 are shown in table IV. The measurements were carried out using two types of graphite tubes, equipped both with integrated platforms or L'vov platforms. The results obtained were compared with recommended or certified values using a t-test (at $95 \%$ confidence level). Some systematic differences with the recommended values of humus and moss samples were observed as shown in table IV. There also seem to be some differences according to the platform type used. The reason for these differences is not yet known. The analysis result for the lichen sample did not deviate from the certified value when Method 1C was used. When the sea lettuce sample was decomposed with the Method 1C, a slight white precipitate was observed after decomposition. These kinds of samples probably contain organoarsenic compounds that are
Table II. Recoveries of As in humus and moss samples with a microwave sample decomposition Method 1C. Pyrolytically coated graphite tubes with an integrated platform were used.

\begin{tabular}{ccccccc}
\hline Sample & Program & $n$ & $\begin{array}{c}\text { As / } \\
m g ~ k^{-1}\end{array}$ & $s$ & $\begin{array}{c}\text { RSD/ } \\
\%\end{array}$ & $\begin{array}{c}\text { Recovery/ } \\
\%\end{array}$ \\
\hline Harjavalta humus & A & 3 & 5.02 & 0.19 & 3.8 & 76 \\
$"$ & B & 2 & 5.98 & 0.05 & 0.8 & 91 \\
$"$ & C & 3 & 7.02 & 0.15 & 2.1 & 106 \\
Puolanka humus & A & 3 & 1.26 & 0.04 & 3.2 & 72 \\
" & B & 2 & 1.39 & 0.12 & 8.7 & 79 \\
" & C & 3 & 1.57 & 0.09 & 5.7 & 89 \\
Harjavalta moss & A & 6 & 0.70 & 0.04 & 5.7 & 71 \\
" & B & 3 & 0.75 & 0.03 & 4.0 & 77 \\
" & C & 3 & 0.81 & 0.06 & 7.4 & 83 \\
\hline
\end{tabular}

Table III. Recoveries for aqueous arsenic standards.

\begin{tabular}{lccc}
\hline Method & $\boldsymbol{1 C}$ & $\boldsymbol{1 C}$ & $\boldsymbol{2}$ \\
\hline Replicates & 3 & 4 & 4 \\
Dilution volume/ ml & 25 & $25 / 50$ & 50 \\
Platform type & L’vov $^{*}$ & L’vo $^{\prime}$ & Integrated \\
Recovery/ \%* & $106 \pm 1$ & $105 \pm 4$ & $99 \pm 5$ \\
\hline
\end{tabular}

* $95 \%$ confidence intervals are given

more difficult to decompose and therefore a result was obtained that was too low [21] The sea lettuce sample was completely dissolved with the Method 2 and agreement with the certified value was obtained (Tab. IV).

The stability of the decomposed samples (Method 1C) was tested by analyzing a triplicate sample of Harjavalta moss during a three-week period. The decomposed samples were stored at room temperature in polyethylene bottles. A clear trend of the behaviour of arsenic concentration during storage cannot be seen (Fig. 4). Rather, random errors cause some variations in the measured concentration.

\section{Conclusions}

Both microwave decomposition methods studied are suitable for the decomposition of plant materials in bioindicator studies. It was demonstrated that, although some residue was left, Method 1, Program $\mathrm{C}\left(\mathrm{HNO}_{3}\right.$ and $\left.\mathrm{H}_{2} \mathrm{O}_{2}\right)$ suits humus, lichen and moss samples, since good recoveries for arsenic were obtained. The sea lettuce sample was not completely decomposed using Method 1C. Instead, hydrofluoric acid had to be included to achieve a complete dissolution of the sample and a good recovery for arsenic. The sea originating samples contain organo-arsenic compounds that are very difficult to decompose.

Non-spectral interference could be eliminated with the use of high ashing temperatures. When low concentrations 


\section{Original articles}

Table IV. Results of arsenic determinations on different samples using Methods $1 \mathrm{C}$ and 2.

\begin{tabular}{|c|c|c|c|c|}
\hline Sample & Platform type & $\begin{array}{c}\text { Certified or } \\
\text { recommended value } \\
\text { mg/kg }\end{array}$ & $\begin{array}{c}\text { Value obtained } \\
\text { (Method } 1 C) \\
\mathrm{mg} / \mathrm{kg}\end{array}$ & $\begin{array}{l}\text { Value obtained } \\
\text { (Method 2) } \\
\text { mg/kg }\end{array}$ \\
\hline Humus $\mathrm{H}$ & $\begin{array}{l}\text { Integrated } \\
\text { L'vov }\end{array}$ & $6.6 \pm 0.6$ & $\begin{array}{l}7.47 \pm 0.83(n=8) \\
8.14 \pm 0.35(n=13)^{\mathrm{a}}\end{array}$ & $7.43 \pm 0.63(n=9)$ \\
\hline Humus $\mathrm{P}$ & $\begin{array}{l}\text { Integrated } \\
\text { L'vov }\end{array}$ & $1.76 \pm 0.04$ & $\begin{array}{l}1.62 \pm 0.08(n=5) \\
1.84 \pm 0.22(n=11)\end{array}$ & $1.64 \pm 0.11(n=9)$ \\
\hline Moss $\mathrm{H}$ & $\begin{array}{l}\text { Integrated } \\
\text { L'vov }\end{array}$ & $0.98 \pm 0.07$ & $\begin{array}{l}0.75 \pm 0.05(n=15)^{\mathrm{a}} \\
0.90 \pm 0.05(n=11)^{\mathrm{a}}\end{array}$ & \\
\hline Moss $\mathrm{Pb}$ & $\begin{array}{l}\text { Integrated } \\
\text { L'vov }\end{array}$ & $0.105 \pm 0.007$ & $\begin{array}{l}0.138 \pm 0.016(n=4)^{\mathrm{a}} \\
0.130 \pm 0.041 \quad(n=6)^{\mathrm{a}}\end{array}$ & \\
\hline $\begin{array}{l}\text { Sea lettuce } \\
\text { Lichen }\end{array}$ & $\begin{array}{l}\text { L'vov } \\
\text { L'vov }\end{array}$ & $\begin{array}{l}3.09 \pm 0.20 \\
0.85 \pm 0.07\end{array}$ & $\begin{array}{l}2.71 \pm 0.11 \quad(n=5)^{\mathrm{a}} \\
0.85 \pm 0.08 \quad(n=10)\end{array}$ & $3.01 \pm 0.18(n=7)$ \\
\hline
\end{tabular}

$\mathrm{H}=$ Harjavalta, $\mathrm{P}=$ Puolanka.

a Systematic difference with the recommended/certified value is observed (95\% confidence level)

b The moss sample from Puolanka was determined using standard addition method

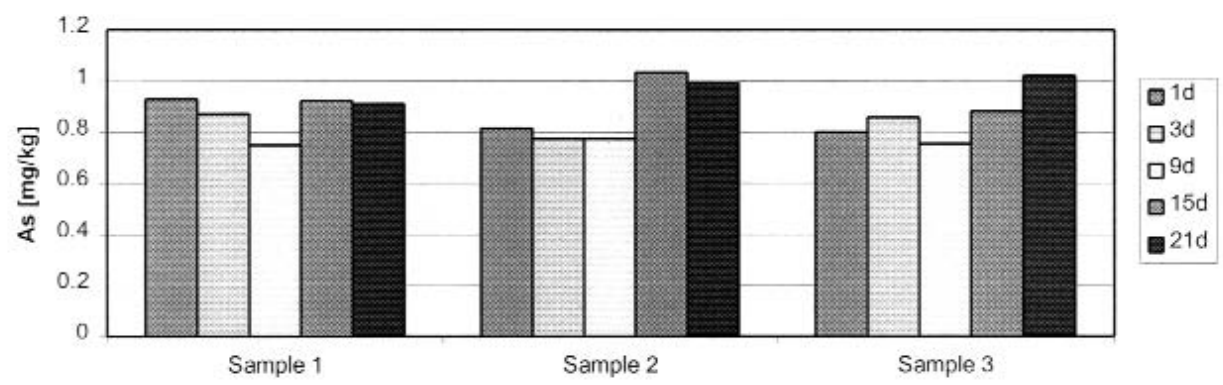

Figure 4. The recovery of arsenic in decomposed Harjavalta moss samples after different storage periods (up to three weeks). Samples were decomposed using Method 1C.

of arsenic are measured, the flat absorption signals obtained make quantification inaccurate. A more dilute modifier solution might help in this context. Also, the very low levels of arsenic in most environmental samples result in very low arsenic concentrations in the decomposed samples, and therefore the determination by GFAAS is inaccurate. It would be advantageous if sample masses higher than $0.5 \mathrm{~g}$ could be decomposed. This study is in progress.

\section{References}

1. Leonard, A. In: Metals and Their Compounds in the Environment: Occurence, Analysis, and Biological Relevance; Merian, E. Ed., Weinheim: VCH Verlagsgesellschaft GmbH, 1991, Chap. II 3.

2. Rühling, Å; Steinnes, E. (Eds.) Atmospheric Heavy Metal Deposition in Europe 1995-1996, Nord 1998, 15, 66.

3. Ackley, K.I.; B`Hymer, C.; Sutton, K.L.; Caruso, J.A. J. Anal. At. Spectrom. 1999, 14, 845.

4. Dagnac, T.; Padro, A.; Rubio, R.; Rauret, G. Anal. Chim. Acta 1998, 364(1-3), 19.

5. Slaveykova, V.I.; Rastegar, F.; Leroy, M.J.F. J. Anal. At. Spectrom. 1996, 11, 997.

6. Saeed, K.; Thomassen, Y. Anal. Chim. Acta 1981, 130, 281.

7. Martinsen, I.; Radziuk, B.; Thomassen, Y. J. Anal. At. Spectrom. 1988, 3, 1013.

8. Letourneau, V.A.; Joshi, B.M.; Butler, L.C. At. Spectrosc. 1987, 8, 145.
9. Steinnes, E.; Rühling, Å.; Lippo, H.; Mäkinen, A. Accred. Qual. Assur. 1997, 2, 243.

10. Matusiewicz, H.; Sturgeon, R.E.; Berman, S.S. J. Anal. At. Spectrom. 1989, 4, 323.

11. Kingstonn H.M.; Haswell, S.J. (Eds) Microwave Enhanced Chemistry: Fundamentals, Sample Preparation, and Applications; Washington, DC: American Chemical Society, 1997.

12. Lippo, H.; Jauhiainen, T.; Perämäki, P. At. Spectrosc. 1997, 18, 102.

13. Bozsai, G.; Schlemmer, G.; Grobenski, Z. Talanta 1990, 37, 545.

14. Bettinelli, M.; Baroni, U.; Pastorelli, N. J. Anal. At. Spectrom. 1988, 3, 1005.

15. Welz, B.; Schlemmer, G.; Mudakavi, J.R. J. Anal. At. Spectrom. 1988, 3, 695.

16. Riley, K.W. At. Spectrosc. 1982, 3, 120.

17. Jauhiainen, T. Determination of Mercury in Environmental Samples by CVAAS, MSc Thesis, Univ of Oulu, Dept of Chem, Oulu, 1998 (in Finnish).

18. Zunk, B. Anal. Chim. Acta 1990, 235, 337.

19. Bettinelli, M.; Spezia, S.; Bizzarri, G. At. Spectrosc. 1996, 17, 133.

20. Wu, S.; Zhao, Y.-H.; Feng, X.; Wittmeier, A. J. Anal. At. Spectrom. 1996, 11, 287.

21. Damkröger, G.; Grote, M.; Janßen, E. Fresenius J. Anal. Chem. 1997, 357, 817. 